\title{
Cloud Based Performance Data Analysis and Monitoring System for Express Bus in Malaysia
}

\author{
Rosilah Hassan , Husna Inani Abdul Jabar", Mohammad Khatim Hasan\#, Meng Chun Lam, Wan Mohd \\ Hirwani Wan Hussain* \\ \# Fakulti Teknologi dan Sains Maklumat, Universiti Kebangsaan Malaysia, 43600 Bangi, Selangor, Malaysia. \\ E-mail:rosilah@ukm.edu.my; husnainani@gmail.com;mkh@ukm.edu.my: lammc@ukm.edu.my \\ *Graduate School of Business, Universiti Kebangsaan Malaysia, 43600 Bangi, Selangor, Malaysia. \\ E-mail:wmhwh@ukm.edu.my
}

\begin{abstract}
Road accidents are often associated with developing countries. One of the developing countries with high traffic accidents is Malaysia. Buses are also no exception in cases of road accidents. Express buses are the main public transportation used by Malaysians to move to other states. However, many road accidents involve express buses arise from driver attitudes, uncertain weather conditions, bus health conditions, and the road environment. Thus, the study was conducted to design and build prototype cloudbased monitoring systems that could analyze the raw data received. The study can help the bus management to monitor the health of the bus in real-time using Big Data Analysis technology using the appropriate cloud-computing platform. This study was conducted to develop an express bus analysis and monitoring system in Malaysia, where the system would have a dashboard that would produce the analysis of raw data (strain and time value) from the Internet of Things (IoT) tools such as sensors, smartphones, and others in the form of info-graphics. The results of this study indicate that rural travel has resulted in the deformation of equipment and hardware such as engines or tires due to the high strain percentage of $321.49 \%$. Therefore, buses that use rural roads are more comfortable to experience damage. For cities and highways, the strains are low with negative values where the city has a percentage of $1.69 \times 10-2 \%$ and the highway has a percentage of $-1.98 \times 10-3 \%$, with the very low rate, deformation will not occur in a short time, so the equipment and the hardware will be in good condition for a long period. In conclusion, this study has succeeded in generating an analysis and monitoring prototype system, as well as this analytical and monitoring system design can be used in the real phase of developing the system.
\end{abstract}

Keywords — big data; IoT; application; smartphone; cloud computing; analysis.

\section{INTRODUCTION}

Road accidents are the ones that often threaten people's lives. Developing countries are often associated with high traffic accident cases. Malaysia is one of the developing countries that have high traffic accident rates [1]. The case increases in road accidents involving buses are one of the causes of death rates in Malaysia. These accidents are often linked to the attitude of bus drivers, bus driving techniques, engine problems, tire conditions, and relevant infrastructure conditions. Express bus travel time also plays a significant role. In the event of traffic congestion, express bus trips are delayed and cause users late to reach their destination. This Fig. 1 is data collected by the Land Public Transport Commission (SPAD) and the Ministry of Transport Malaysia on road accidents.
Fig. 1 shows an increase in road accidents occurring annually [2]. Construction of a consumer perception application will help to reduce the occurrence of express buses accident. This application needs a review of the data to be created and subjective feedback is taken from interviews and questionnaires to have a better understanding of the user's needs about the application. Bus conditions, relevant infrastructure condition, and bus drivers are the factors that need to focus on when building the app. Other than that, the important thing in the construction of this application is the variable in the situation of the decision-making process when using the express bus service [3]. Future investment by improving existing express bus policies with variable data such as waiting time, reliability and travel time. The data collected by using the app can have a positive impact on the quality of express bus services. 


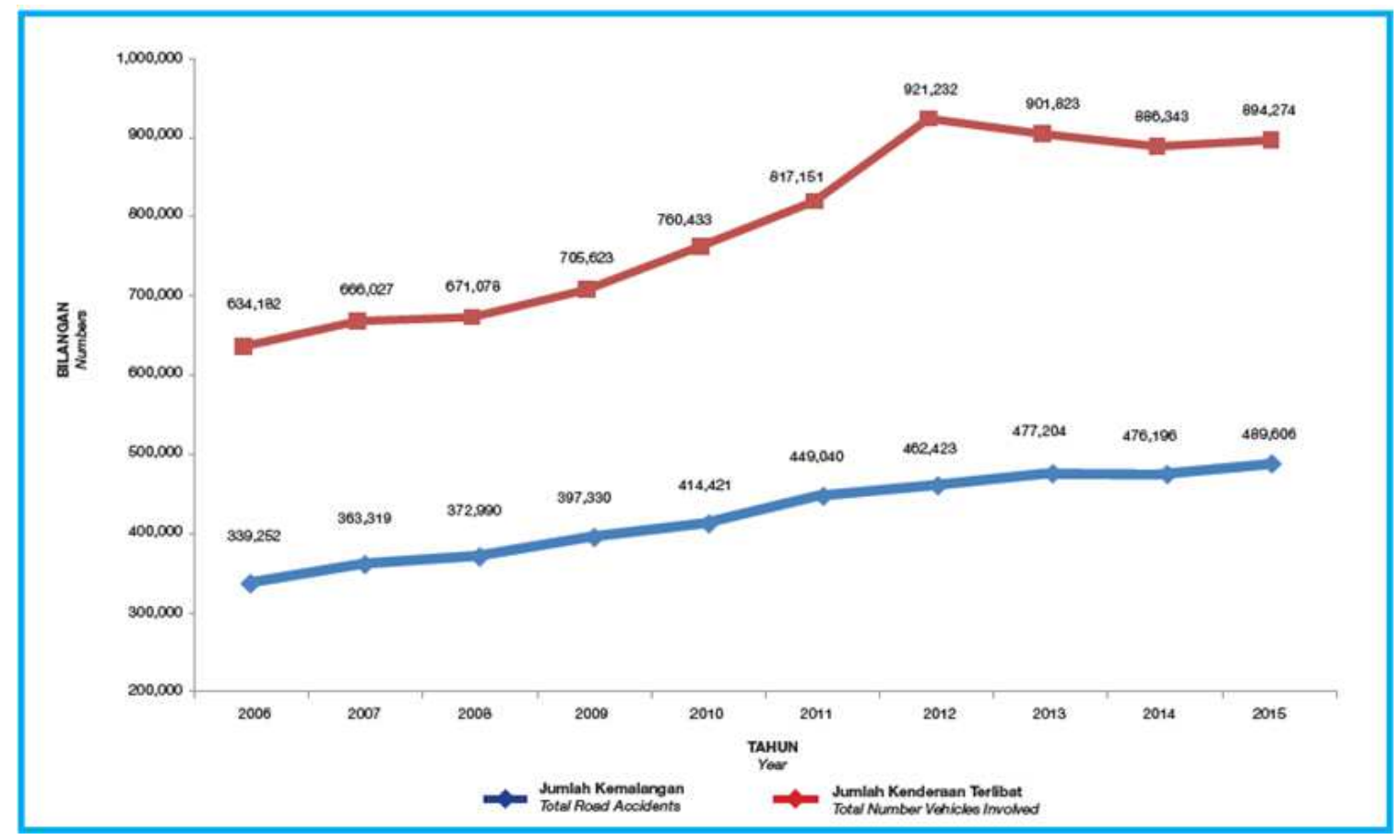

Fig. 1 Vehicles involved in accidents (2006 -2015)

After the construction of the application, the data would be stored in the cloud, retrieved in real-time, and the analysis can be done. These are the reason to build a cloud-based monitoring system prototype where the data collected in the cloud would be reviewed and shown in the dashboard as illustrated in Fig. 2.

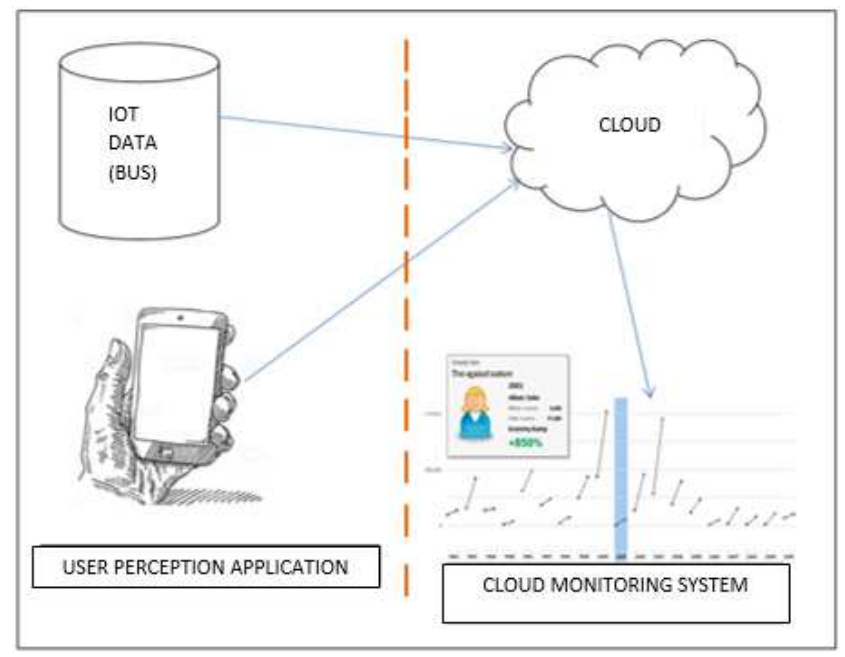

Fig. 2 Development of the Express Bus Management System

Concepts like public computing and computing are always there and the Internet of Things has improved the use of data warehouses for analysis and research. This makes excellent details of the information that can be adopted using Great Data Analysis technology by utilizing the appropriate public computing platform [4]. This technology allows service providers to visualize the statistics of Internet of Things data as well as from user perception apps. Other than that, public infrastructure providers can visualize the performance of platform components such as servers and networks. Then, the data contained in the cloud can provide solid evidence of system and application behavior based on observation of objective data.

Many road accidents involve express buses arise from risk-taking drivers, bus driver negligence, unmanageable drivers, uncertain weather conditions, and much more. This is a significant part of ensuring that express bus travels are safer. Besides, the condition of the bus in terms of engine and tires, as well as uneven and perforated road conditions can be one of the reasons for road accidents. Therefore, the solution path should be studied by looking for this existing framework to build a monitoring system prototype that is appropriate for this study.

This study is to answer three questions as follows:

- What kind of software is used to build the prototype and to analyze the data?

- Does the prototype monitoring system manage to be linked to the web server that exists in the cloud environment?

- Will this prototype monitoring system be able to display the important statistic of the raw data (strain and time)?

The research was conducted to achieve two objectives, which are first to design and build a cloud-based monitoring system prototype and secondly to analyze raw data (strain and time) in the cloud environment. The research focuses on three scopes, which are,

- Understanding important factors relating to road accidents involves express buses.

- Develop a prototype of the cloud-based monitoring system.

- Analyze the Internet of Things data.

This study expects the system to have a positive impact on reducing the occurrence of express bus accidents on the road. This is because the collection of these data can help to analyze the causes of road accidents involving the express buses and improve the safety of the express buses on the road. Through this study, the analysis will help in 
understanding what needs to be considered so that the system will be more organized and the safety of express buses on the road will be more secure.

\section{A. Road Accident}

Road accidents are incidents that frequently read and seen through mass media and print media. This often happens in developing countries. The increase in road accidents around the world in decades is in a worrying matter [5]. However, this is inevitable because of national development and increase usage of vehicles on the road. In Malaysia, road accidents also increased; Table 1 found that the number of bus accidents on the way ranged from 8,000 to 10,000 buses annually [2].

TABLE 1

AFFECTED VEHICLES (2006 - 2015)

\begin{tabular}{|l|l|l|l|l|l|l|}
\hline Year & Bike & Car & Bus & SUV & Others & Total \\
\hline 2006 & 104,107 & 411,444 & 9,700 & 20,885 & 88,046 & 646,448 \\
\hline 2007 & 111,765 & 426,941 & 10,285 & 21,823 & 95,213 & 666,027 \\
\hline 2008 & 111,819 & 435,665 & 9,356 & 22,793 & 91,445 & 671,078 \\
\hline 2009 & 113,962 & 472,307 & 9,380 & 23,581 & 86,393 & 705,623 \\
\hline 2010 & 120,156 & 511,961 & 9,580 & 25,777 & 93,059 & 760,433 \\
\hline 2011 & 129,017 & 546,702 & 9,986 & 30,828 & 100,618 & 817,151 \\
\hline 2012 & 130,060 & 655,813 & 10,617 & 32,891 & 91,831 & 921,232 \\
\hline 2013 & 121,700 & 632,602 & 10,123 & 52,512 & 84,886 & 901,823 \\
\hline 2014 & 125,712 & 617,578 & 9,193 & 41,464 & 92,396 & 886,343 \\
\hline 2015 & 123,408 & 625,758 & 8,804 & 46,163 & 55,219 & 894,274 \\
\hline
\end{tabular}

*Others include bicycle, lorry, van, and taxi

Source: Traffic branch Bukit Aman

Hence, many studies have been done to identify the problems and causes of road accidents and ways to prevent accidents for the future. The studies are conducted in urban and rural areas using various factors that can be analyzed such as speed limits, weather, age, street lighting, traffic movement, road conditions, junction types, surface conditions of the road and driver behavior. Road accident cases in the city were due to several important factors i.e. the average travel speed, the speed signboard shown on the road, the median width, the road surface type, the street lighting during day and night, total vehicles per hour, number of pedestrian crossing facilities, and percentage of trucks or Lorries on the road [6].

Whereas in rural areas, examine factors such as road geometry and traffic mass [7]. In addition, the age difference factor in visual scanning on the middle-class highway also needs to be examined [8]. Various factors can cause a person to face a road accident. These risk factors can be analyzed using three types of analytical frameworks used by the World Health Organization (WHO):

- Public health approach

- Haddon Matrix

- System approach

1) Public Health Approach: This public health approach is used to understand an event and to solve the problem by studying and implementing appropriate testing. This public health approach can produce an analytical framework that can assist in solving issues encountered [9]. In addition, this approach can reduce the occurrence of injury in an accident
[10]. Fig. 3 illustrates the four steps that need to be followed when using this public health approach.

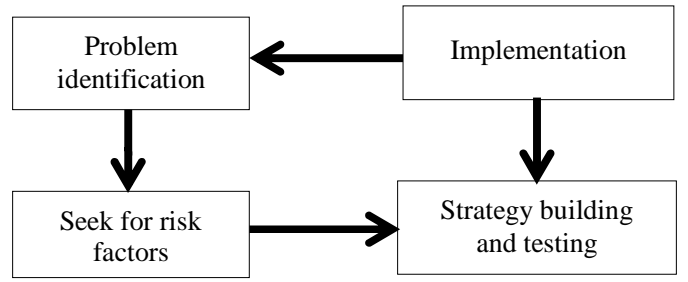

Fig. 3 Public Health Approach

The first step is to identify the problem. This problem needs to be seen from various angles not only counting the percentage of cases but identifying the people involved, the losses they face, the degree of injury and the nature of the scene. Next, look for factors that increase the risk of accidents or injuries. Then based on the found factors, some preventative measures can be suggested, expressed, and tested. Finally, the implementation of prevention tested through clinical and small-scale to reduce the occurrence of accidents in the area.

2) Haddon Matrix: Apart from the public health approach, Haddon Matrix is one of the analytical frameworks that can be used to detect road accident factors. A matrix developed by William Haddon in 1980 described to detect risk factors before the accident, during the accident and after the accident [11]. This Haddon Matrix shows how to analyze crashes systematically. Table 2 shows the three-phase of the study which is before, during and after the accident, as well as the factors, need to consider in the overall accident.

TABLE II

HADDON MATRIX

\begin{tabular}{|c|c|c|c|}
\hline \multirow[t]{2}{*}{ Phase } & $\begin{array}{l}\text { before the } \\
\text { accident }\end{array}$ & $\begin{array}{l}\text { during } \\
\text { accident }\end{array}$ & after accident \\
\hline & $\begin{array}{l}\text { Accident } \\
\text { Prevention }\end{array}$ & $\begin{array}{l}\text { Prevention of } \\
\text { injury during } \\
\text { the accident }\end{array}$ & Preserve life \\
\hline People & $\begin{array}{l}\text { - Information } \\
\text { - Attitude } \\
\text { - Inequality } \\
\text { - Police } \\
\text { enforcement }\end{array}$ & $\begin{array}{l}\text { - Use barrier } \\
\text { - Inequality }\end{array}$ & $\begin{array}{l}\text { - First aid } \\
\text { skills } \\
\text { - Access to } \\
\text { medicine }\end{array}$ \\
\hline $\begin{array}{l}\text { Vehicles and } \\
\text { equipment }\end{array}$ & $\begin{array}{l}\text { - } \text { Road } \\
\text { suitability } \\
\text { - } \text { Lighting } \\
\text { - Brake } \\
\text { - Control } \\
\text { - Speed } \\
\text { management }\end{array}$ & $\begin{array}{l}\text { - Occupy } \\
\text { blockers } \\
\text { - Other } \\
\text { safety } \\
\text { equipment } \\
\text { - Accident } \\
\text { protection } \\
\text { design } \\
\end{array}$ & $\begin{array}{l}\text { - Accessibility } \\
\text { - Fire risk }\end{array}$ \\
\hline Environment & $\begin{array}{l}\text { - Road design } \\
\text { and road } \\
\text { layout } \\
\text { - Speed limit } \\
\text { - Pedestrian } \\
\text { facilities }\end{array}$ & $\begin{array}{l}- \text { Objects of } \\
\text { roadside } \\
\text { accidents }\end{array}$ & $\begin{array}{l}\text { - Rescue } \\
\text { facilities } \\
\text { - Congestion }\end{array}$ \\
\hline
\end{tabular}

3) System Approach: This system approach is a risk analysis conducted simultaneously. Using the Haddon Matrix approach as a basis before developing the system and then structuring the relationships of factors involving the people, vehicles, and incident events to examine more 
factors for road accident prevention. Fig. 4 shows the system approach.

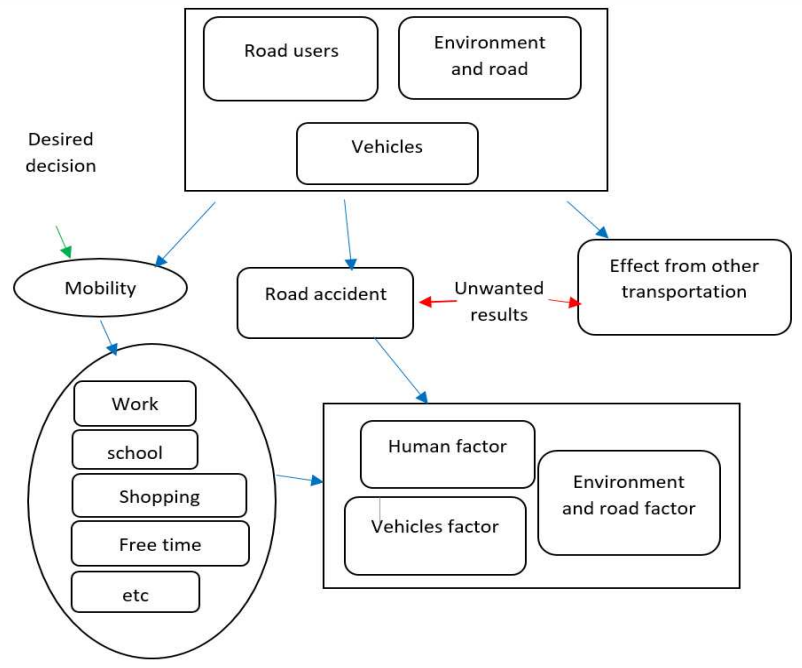

Fig. 4 System Approach

\section{B. Express Bus}

Express buses are one of the public transports used to move to distant places. The express bus service is a long journey away and stops at the bus designated venue [12]. However, the express bus has no exception from road accidents. Several factors need to be taken into consideration to improve the safety level of express buses. Factors include the management of buses and bus drivers, bus health, environmental conditions, and service quality. Fig. 5 shows the express bus safety factors.

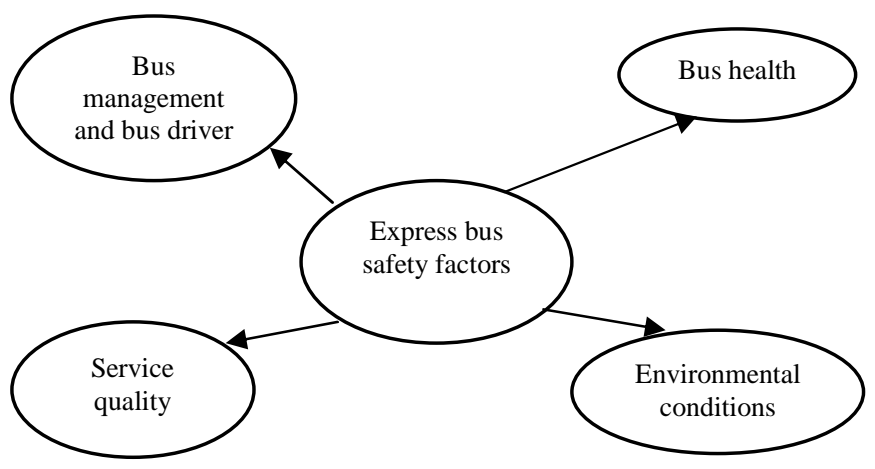

Fig. 5 Express bus safety factors

1) Bus Management and Bus Driver: The less disciplined bus drivers often do something according to their feelings. These bus drivers usually try to satisfy their needs on the road or in parts of their lives [13]. Therefore, it makes them dare to drive speedily and dangerously. Some other risk factors on roads can be attributed to the bus driver, such as fatigue, cell phone use, and health problems. The thing that needs to be understood is the attitude of the bus driver to understand the additional motives of the bus driver while on duty. The most dangerous thing is the extra motive that makes the bus driver perform something that can trap his passenger life such as the action they try to save the travel time and energy. The bus driver tends to increase the speed of the bus without thinking about the safety of his passengers. Besides, driving dangerously has become common in bus management as most drivers do the same thing. Therefore, bus management plays an essential role in providing good and safe service. Thus, the management must take good action in handling recommendations and complaints from passengers, as well as giving appropriate briefings and training about safety to bus drivers. This activity may help the bus driver to improve their service to ensure the safety of these express bus users.

2) Bus Health: The buses need to be maintained to ensure the best quality for every bus trip. Buses used in the public transportation industry have different brands, manufacturer and ages [14]. There are buses used for long distances, between the city and the rural areas. Every trip is not the same for every bus, some may be going through rough roads and some through better roads. The important thing in maintaining the bus's health is to ensure the safety of passengers are the bus age, bus travel distance after each service check, engine condition, bus equipment condition and overall bus condition. Before 2008, no law said the express buses needed to be equipped with a seatbelt, but after 2008, the Road Transportation Authority (JPJ) has confirmed the law that expresses busses need to have a seatbelt in each passenger seat because it can prevent injury of the head, shoulders, and waist of the passengers [15].

3) Road Condition: The road conditions and environment also play a major role in bus care. Besides, this could also cause a bus crash because some of these buses had to use the roads in bad condition [14]. Other than that, the degree of night vision in dark areas causing bus drivers to use the high beam to look the road ahead, but in the meantime, this causes the bus driver's vision diminished due to the glare [16]. Also, uncertain weather conditions are one of the worst points of view as the degree of vision will decrease in weather conditions such as heavy rain. Improve road barrier standards, relocation of toll plazas, reduce tree planting in small areas of roads are few ways to improve road safety [17].

4) Service Quality: The quality of these services includes various factors such as service coverage, service time, and safe bus travel. The public transport options that consumers want to use are influenced by bus service quality [12]. Previously, users were satisfied with the buses on the streets that are often used by bus users but now users want efficient bus management. Besides, the questionnaire can improve the existing bus service quality by getting a response from bus users about comfort and the safety feeling of the bus and the trip. Therefore, the quality of bus service is important to ensure the safety and comfort of passengers when traveling.

\section{Vehicle Health Monitoring}

To prevent accidents from occurring, proper inspections and maintenances are needed to make sure the express bus is in good shape on every trip. Therefore, vehicle health monitoring is important to identify problems or damages of vehicles before significant accidents can occur.

Monitoring of the vehicle's health is a process of implementing a vehicle's destructive movement strategy 
whereby this system can capture predictable vehicle conditions as well as current conditions. Then the information is used to improve operational results, support actions and business performance [20]. These health data are collected from equipment, structure and vehicle elements. Collected data is then used for diagnosis and prediction of vehicle health for the present and future. This information is further processed to formulate appropriate operations and determine the work to be done to resolve the occurrence or eventual damage.

This vehicle health monitoring system consists of sets of sensors and data processing of hardware and software distributed between vehicles and support systems. This sensor is used to measure the state consciousness variables that indicate the potential for failure mods. Additionally, identify components that do not work in the vehicle. Furthermore, sensors are also used for controls and monitoring such as temperature, speed and sensor flow rate which is also crucial in reducing the risk of damage. These data can be moved quickly and quickly with specific protocols such as IEEE 802.11 that foster intensive use of wireless sensor networks. There are four important aspects of in-vehicle health assessment, namely driver and passenger, road features, vehicle characteristics and environment [21]. Some examples of studies that can be linked to the four aspects above such as the in-depth study of road accident factor analysis and road features that can cause accidents.

\section{MATERIALS AND METHOD}

The study starts with identifying problems and finding factors of road accidents involving an express bus. Next, collecting raw data from the selected express bus company. After that, the development of the monitoring system and analyzing data. Lastly, the implementation process with a dashboard display.

\section{A. Identifying Factors and Problems}

Road accidents involving express buses occur due to the risk of driver behavior, bus driver negligence, unmanageable drivers, uncertain weather conditions and much more. This is a major part of ensuring that express bus travels are safer. In addition, the condition of the engine and tires, as well as uneven and perforated road conditions can be one of the reasons for road accidents. Therefore, to reduce the occurrence of accidents involving express buses is to monitor for every express bus trip and analyze data obtained using a cloud-based monitoring system by bus management and enforcement in real-time. The idea is to build a cloudbased monitoring system that facilitates the management to predict and monitor the health of express buses. The method used to identify problems and factors is to refer to other relevant research references such as journals, articles, via the internet and others

\section{B. Collecting Data}

After identifying problems and factors, the data collection was done by the Integrated Design for Advanced Mechanical Systems (PRISMA) from the Faculty of Engineering Universiti Kebangsaan Malaysia (UKM) with selected express bus companies. The data collected is a strain on the suspension using a data acquisition tool. This tool can detect the displacement that occurs from vibrations on each bus trip. These vibrations and displacements can be detected even small or big vibrations. Data obtained are cyclic data for each displacement and vibration detected. In addition, the data obtained is data that has not been processed and the processing of this data can be done using various types of software available but the software is not able to show data in real-time. Fig. 6 is the data acquisition tool used.

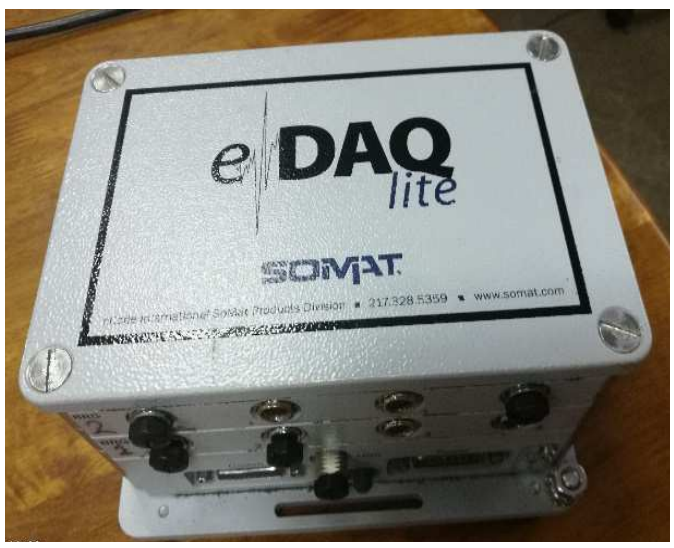

Fig. 6 Data Acquisition Tool

The data provided is in the form of a .csv file where there are only two important rows which are strain value in the microstrain $(\mu \varepsilon)$ and the time in second(s). This .csv file contains more than 30,000 strain and time values. The data received will be entered into the database and the data will be displayed in the dashboard in the form of appropriate graphs.

\section{Development of the Cloud Analysis and Monitoring System Prototype}

The construction of this analysis and monitoring prototype system is divided into four parts, namely system design, cloud architecture, front-end development and backend development. The design describes in detail the construction of the system by using appropriate diagrams. Furthermore, cloud architecture describes in detail the user interaction within the cloud environment and cloud architecture associated with this study. This front-end development is the website used to display dashboards for analysis. management should be noted in the cloud services.

1) System Designs: In this phase, there is a system design that describes the sequence diagram (UML) that shows the data movement in the system. Subsequently, the use case diagram (UCD) describes the role of actors in system development. Finally, a data flow diagram (DFD) describes the journey of data in a database. The data and information that has been analyzed will be displayed to the admin in the form of info-graphics. Infographics are the best way to show Big Data in visual form. For example, data from the database will be displayed using graphs, charts and texts. Besides, the data can also be converted to a .csv file format. Fig 7 shows a sequence diagram for the admin. There are two actors outside and within the system environment as shown by UCD. Both actors are engineers [actor 1] and admin [actor 2]. The process involved outside the system environment is data collection. 


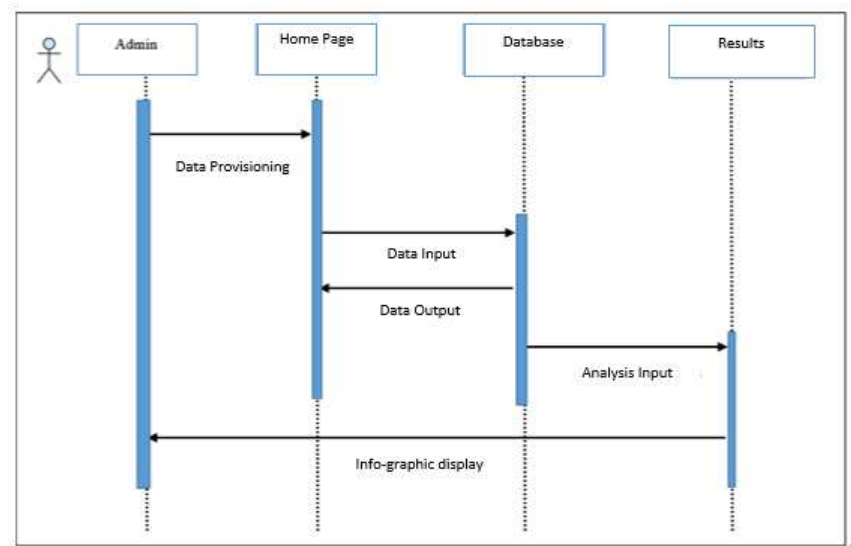

Fig. 7 Shows a sequence diagram for the admin

Whereas, processes involved in the system are data storage, data analysis and decision-making. In summary, the activities of each actor outside and within the system environment are as follows in Fig 8.

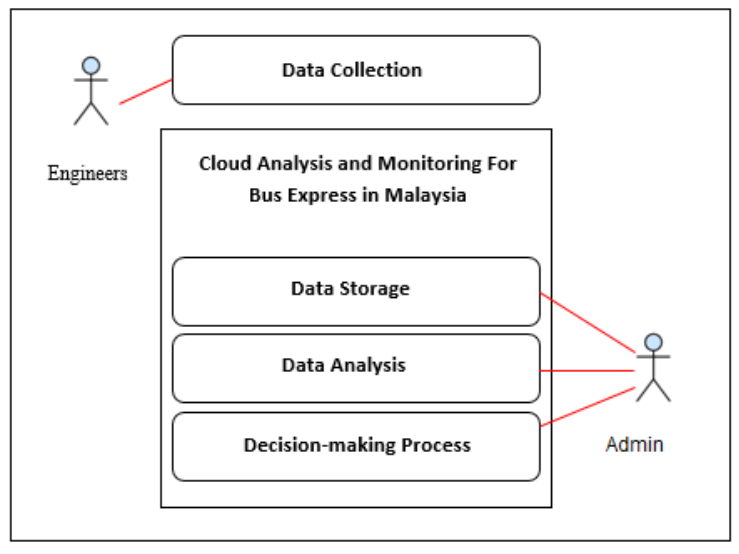

Fig. 8 Use Case Diagram

Data Flow Diagram (DFD) illustrates how the system processes data in terms of input and output. As the name implies, this data flow diagram shows its focus on the flow of information, the origin of the data, data travel and how it is stored. Fig 9 shows the DFD for the Cloud-Based Express Bus Analysis and Monitoring System in Malaysia.

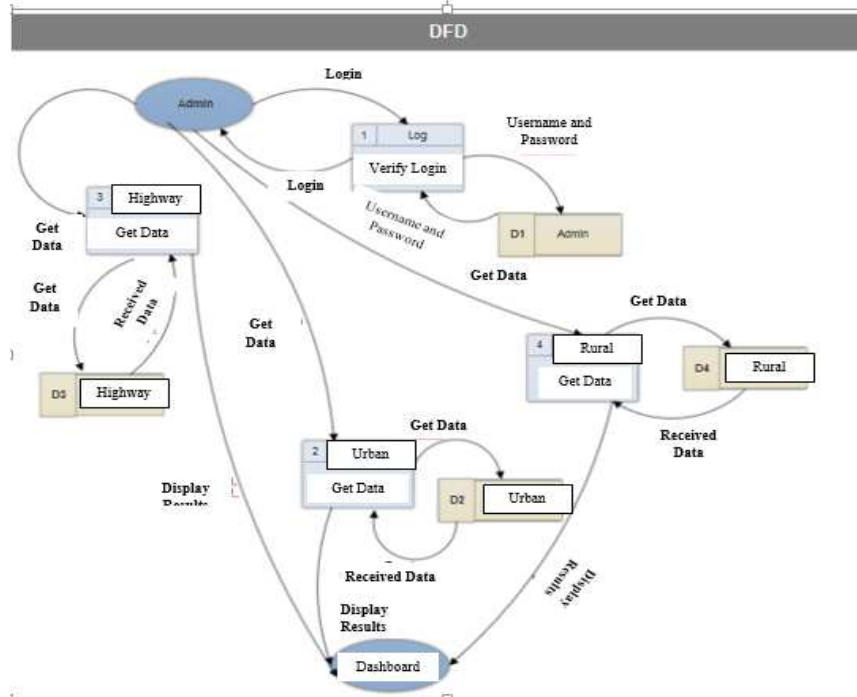

Fig. 9 DFD Cloud Based Express Bus Analysis and Monitoring System in Malaysia
2) Cloud Architecture: This monitoring system is an analysis view created in the cloud environment. Therefore, users need to get cloud access such as Pythonanywhere.com, heroku.com and others that offer platforms as a service (PaaS) for a fee that suits the needs of a system. This cloud environment has an accessible dashboard for users to understand the range of software available when users subscribe to the cloud platform as a service (PaaS). The dashboard has some access that users can use, one of which is the bash console used to install the appropriate app extension. By using this console, users can create virtual environments that can separate different activities. Hence, in a single cloud environment user can create many virtual environments without clashes, most importantly is the amount of cloud storage that users need when subscribing. If users have a bigger budget, users can subscribe and enjoy more privileges each service offered by these cloud services.

Additionally, there is cloud storage where all the important files are stored like many virtual environment files, application extension files and more. Here too, is the place for users to enter the files required to create a system or website. These files can be uploaded and stored in appropriate directories such as newly created raw data, .sql files from databases in localhost, source code, and others. Furthermore, web servers are provided free. However, free web servers do not allow users to change domain names, but users that are subscribed to the services will be privileged to be able to change the domain name according to user preferences.

After that, the database is also given. The database uses the sql console in Pythonanywhere.com and different companies may use various ways and various types of databases. External database administration tools from the cloud environment can be used but it should be seen whether the administration tools of the database are appropriate to the cloud environment used. After the user successfully uploads important files and installs an app extension, users can use analytics and monitoring system successfully. Fig. 10 is the architecture of the cloud-based analysis and monitoring system. The cloud-based analysis and monitoring system will always interact with the cloud environment. Therefore, users can use them anytime and anywhere.

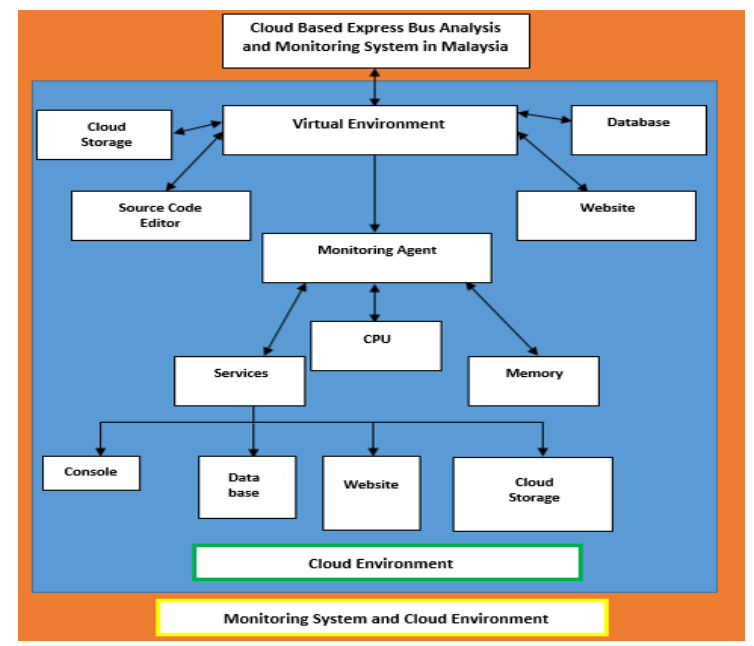

Fig. 10 Cloud Based Express Bus Analysis and Monitoring System in Malaysia Architecture 
3) Front-end Development: Front-line development is a vital part of building this monitoring system. This is where the analysis will be displayed in the dashboard. To facilitate the development of the interface to produce the graphs corresponding to a very large amount of data, Dash by Plot.ly has been selected and used to display the analysis data. No CSS or HTML files are required because everything can be organized into a single file in the programming file using Python 3. Additionally, Dash by Plot.ly is dynamic and uses HTML and CSS automatically and can accommodate very large data as well as data received in real-time. In addition, Python 3 also plays a major role in generating interfaces because Python 3 is the primary programming language used in the development of the analysis and monitoring system. Python 3 imports a lot of functions from a huge library. Among them are Pandas for dynamic mathematical calculations. Next, Dash is used for website interface development. Then, Plot.ly works to launch graph creation.

4) Back-end Development: Back-end development is where all the code is launched, receiving data as well as code that contains the logic for retransmission of info-graphics or appropriate graphs. The three main things that must be in the back-end development are servers, programming software, and databases. The server serves as a host that accepts and issues data. While programming software is a medium used as an intermediary between server and database. The database is where all the data will be stored and recalled when required. The database used in building this analysis and monitoring system is MySQL. MySQL uses Structured
Query Language (SQL). SQL is a programming language used by MySQL to manage databases where data can be added, merged, deleted and others. MySQL is open-source that is easy to use. Next is the programming language used in constructing this analysis and the monitoring system is Python 3. Python 3 is used in both development areas. This Python 3 is used in the Visual Studio Code framework provided by Anaconda. Anaconda is also a Python distributor who distributes programming languages $\mathrm{R}$ and Python openly. Anaconda makes it even easier to work on building the analysis and monitoring system.

\section{Implementation and Development}

This analysis and monitoring prototype system interface has an info-graphics displayed in the dashboard with several functions provided using Dash and Plot.ly when imported into Python 3. The system shows graphs of the raw data collected and displayed it on an optional browser, Mozilla Firefox. The system has been successfully built into the cloud environment and the url of the system is http://ravenlore.pythonanywhere.com/

This analysis and monitoring system dashboard page (dashapp.py) consists of navigation bar attributes such as downloading graphs as pictures in .png files. Additionally, raw data graphs can be further analyzed on the Chart Studio website provided by Plot.ly free. Additionally, this graph can zoom in and zoom out. Next, this graph is automatically scaled using imported and incoming functionality in Python 3. Fig 11 shows the dashboard page.

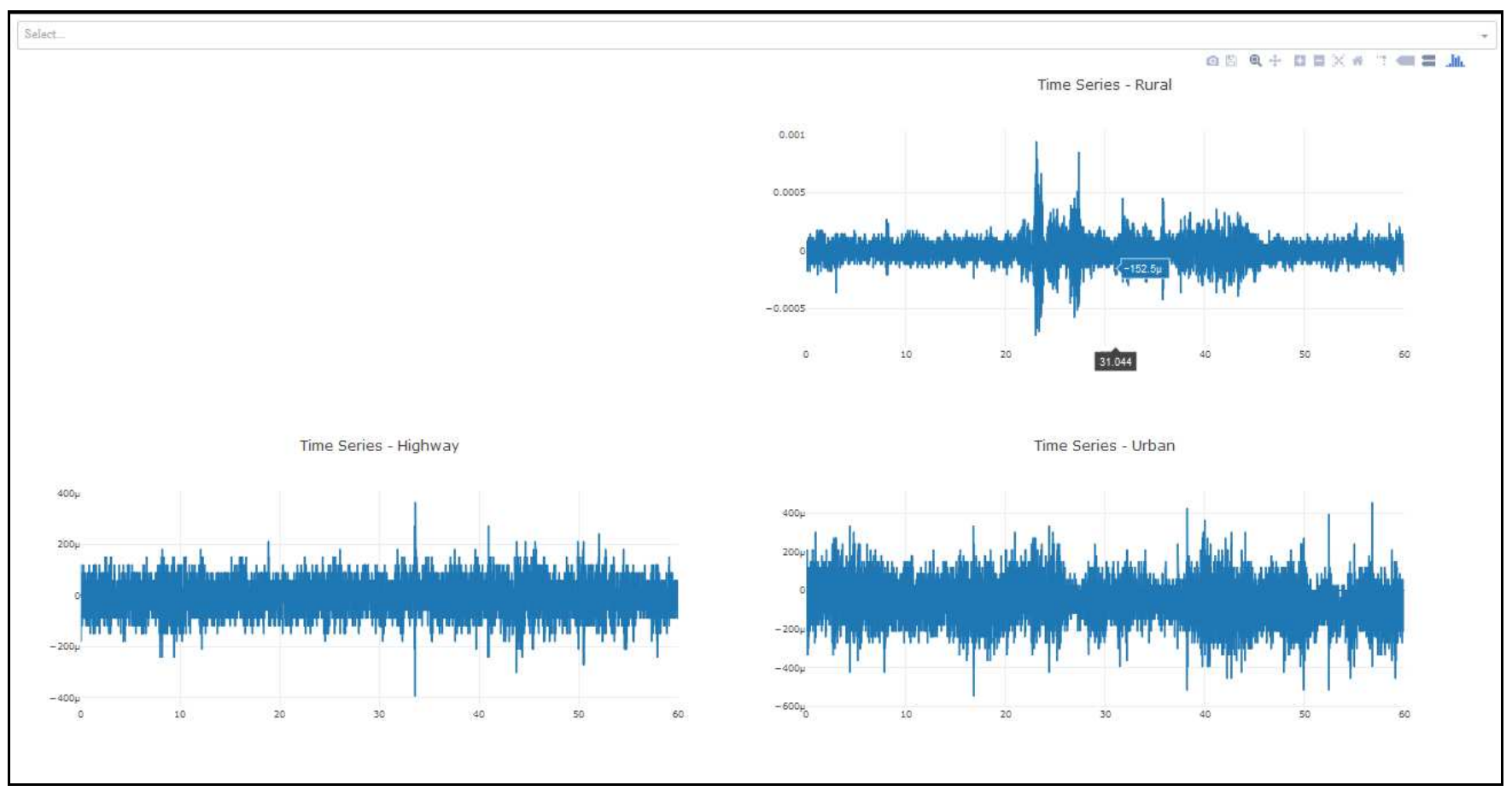

Fig. 11 Dashboard of Cloud Based Express Bus Analysis and Monitoring System in Malaysia

Next is Fig. 12 data analysis in Chart Studio. 


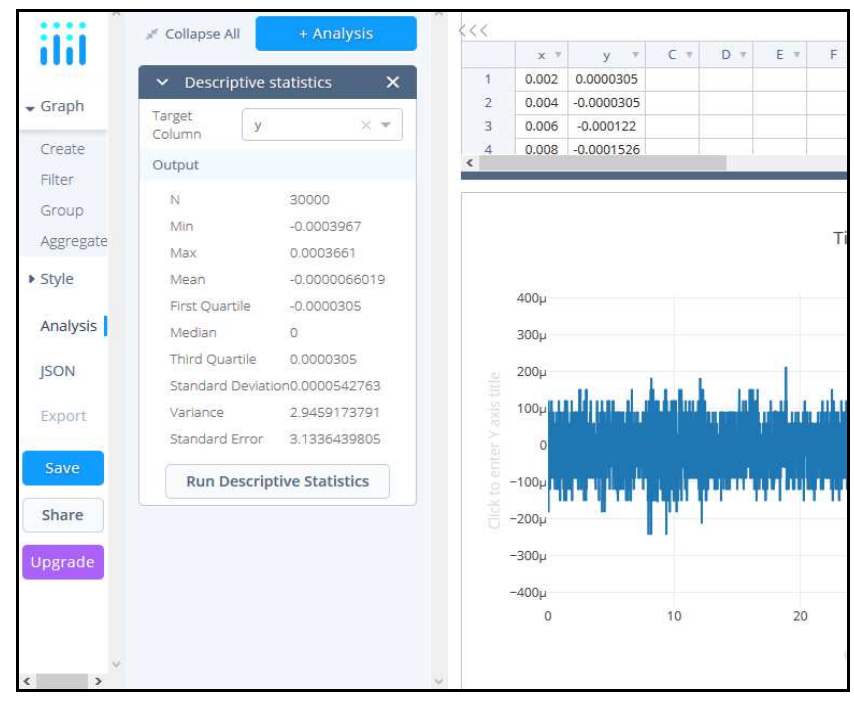

Fig. 12 Data Analysis in Chart Studio

\section{RESULTS AND DISCUSSION}

The purpose of the development of this prototype system is to know the extent to which Big Data can be analyzed within the cloud environment. This prototype is used as an overview to display the analysis and monitoring systems developed. The dashboard is used so that the data can be analyzed and release the necessary statistics. The raw data to be analyzed are data of strain and time for highway, urban and rural roads. Fig. 13 shows the analysis of highway roads, Fig. 14 shows an analysis of urban roads and Fig. 15 is an analysis view of rural roads.

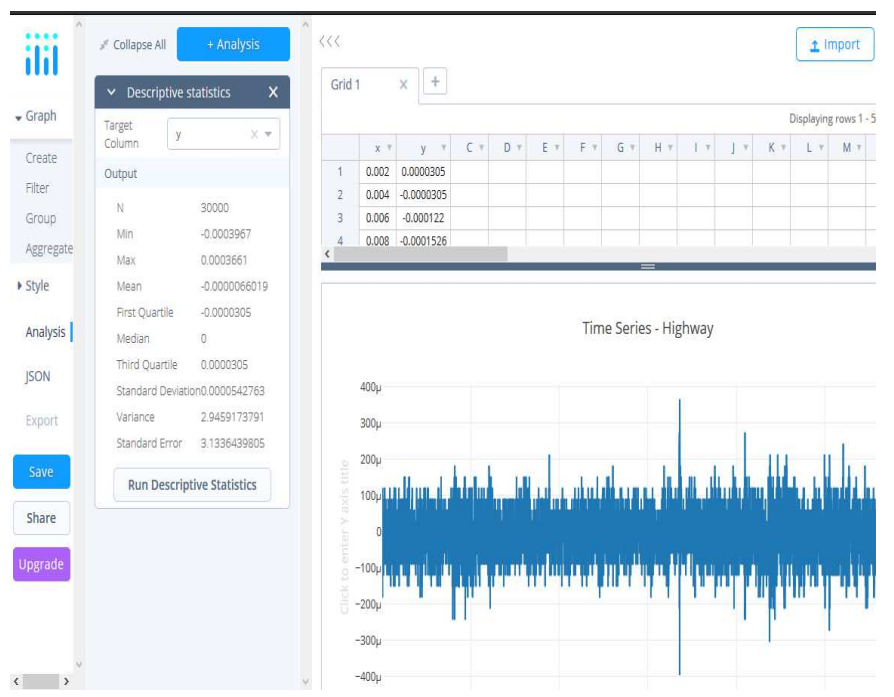

Fig. 13 shows analysis of Highway

Descriptive Statistic that is obtained from Chart Studio for highway roads raw data based on the Fig. 13 are as following $\min =-0.0003967$, $\max =0.0003661$, mean $=-$ $0.0000066019, \quad$ standard deviation $=0.0000542763$. Descriptive Statistic that is obtained from Chart Studio for rural roads raw data based on the Fig. 15 are as following $\min =-0.0007323$, $\max =0.000946$, mean $=1.0716333333$, standard deviation $=0.0000812449$. Table 3 is a descriptive statistical comparative table for the three specified areas of highway, city, and rural.

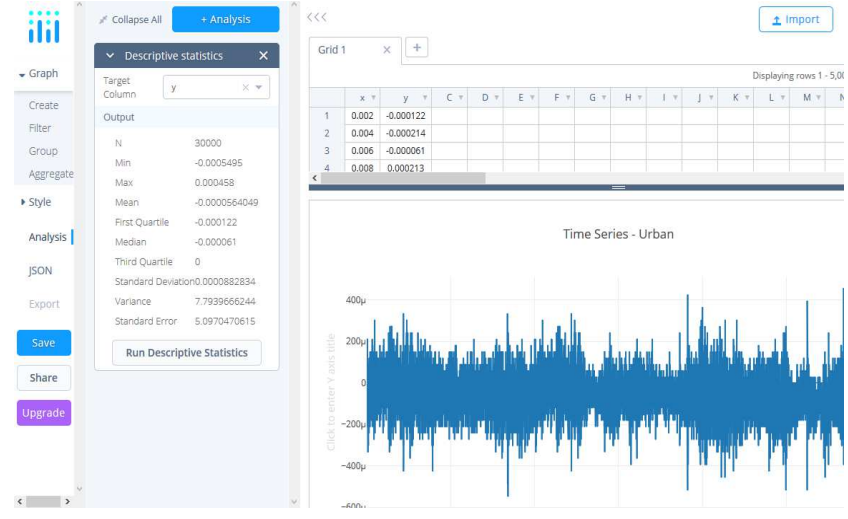

Fig. 14 shows the analysis of Urban

Descriptive Statistics that is obtained from Chart Studio for urban roads raw data based on Fig. 14 are min= 0.0005495 , $\max =0.00045$, mean $=-0.0000564049$, standard deviation $=0.0000882834$.
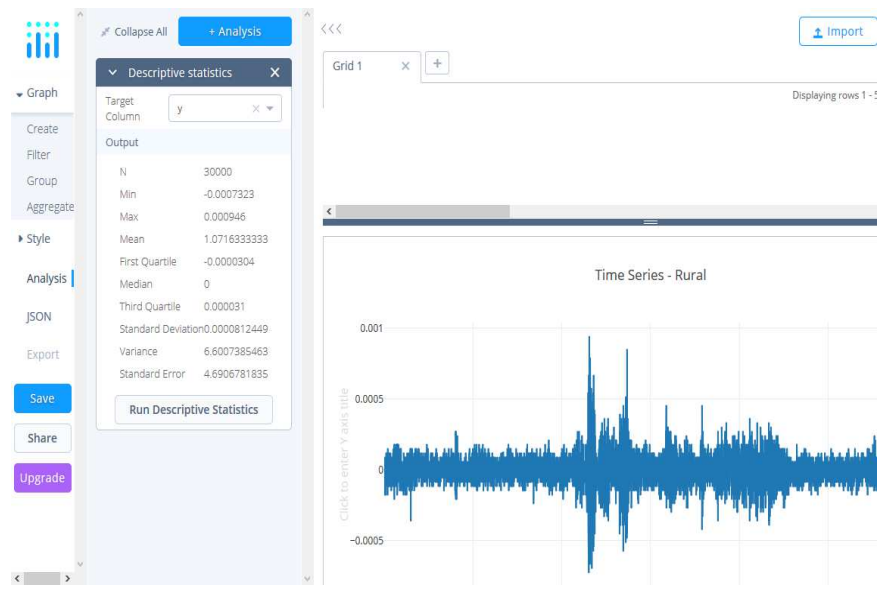

Fig. 15 shows analysis of Rural

TABLE III

DESCRIPTIVE STATISTICAL COMPARATIVE

\begin{tabular}{|c|c|c|c|}
\hline Road Type & Highway & Urban & Rural \\
\hline Amount of Data & 30,000 & 30,000 & 30,000 \\
\hline Minimum $(\mu \varepsilon)$ & -396.7 & -549.5 & -732.3 \\
\hline Maximum $(\mu \varepsilon)$ & 366.1 & 450 & 946 \\
\hline Mean $(\mu \varepsilon)$ & -6.6019 & -56.4049 & $1,071,633.33$ \\
\hline Percentage (\%) & $-1,980.57$ & $-16,921.47$ & $321,489,999$ \\
\hline $\begin{array}{l}\text { Standard } \\
\text { Deviation }(\mu \varepsilon)\end{array}$ & 54.2763 & 88.2834 & 81.2449 \\
\hline Differences & $\begin{array}{l}\text { Highway } \\
\text { have negative } \\
\text { mean wherein } \\
\text { the impact of } \\
\text { triggers and } \\
\text { shakes do not } \\
\text { cause } \\
\text { deformation } \\
\text { from strain }\end{array}$ & $\begin{array}{l}\text { The city has a } \\
\text { negative mean } \\
\text { where the } \\
\text { impact of the } \\
\text { agitator and the } \\
\text { tremors does } \\
\text { not cause } \\
\text { deformation } \\
\text { from the strain }\end{array}$ & $\begin{array}{l}\text { Rural areas have } \\
\text { a positive mean } \\
\text { where the impact } \\
\text { and vibration } \\
\text { cause strain and } \\
\text { deformation on } \\
\text { the hardware and } \\
\text { equipment of the } \\
\text { bus }\end{array}$ \\
\hline
\end{tabular}

Based on Table 3, rural travel causes deformation on equipment and hardware such as engines or tires due to the high average strain. Hence, the bus using country roads is more comfortable to experience damages. For cities and highways, the strains are low with negative values, so the deformation will not happen in a short period, so the 
equipment and hardware of the bus are still in good condition after the trip.

\section{CONCLUSION}

The focus of the research is to design and produce prototypes of cloud-based analysis and monitoring systems. Then we analyze the raw data included in the cloud environment. The case of road accidents involving express buses is increasing. Various factors can be attributed to road accidents involving express buses such as bus management, bus drivers, bus health, road conditions, and service quality. What needs to be improved is safety and comfort in every express bus trip. Based on the research issues discussed, cloud-based express bus analysis and monitoring systems are proposed to help solve this problem. The main contribution of this study is to assist the express bus management to develop the future Cloud-Based Express Analysis and Monitoring System in Malaysia based on the results of the analysis and design of the proposed system.

Research constraints of this study is, analysis of the development of analytical and monitoring systems conducted in this study is limited to UML sequence diagram, applied case diagram and data flow diagram. However, the analysis and monitoring system architecture has been successfully designed. In addition, only a static analysis and monitoring system dashboard was created because of the very limited time and lack of knowledge regarding the programming language used. Finally, constraint in terms of software, the use of free cloud services has some shortcomings such as small cloud storage sizes, CPU usage limits within a day, and limited use of consoles. Overall, this research has succeeded in generating analytics to build an analysis and monitoring system and the design of this analysis and monitoring system can be used in the actual phase of the system development. The findings of this study can also be used as a guide during the actual construction of the system.

\section{ACKNOWLEDGMENT}

This is to acknowledge the support given by Universiti Kebangsaan Malaysia (UKM) through Research Project grant Dana Cabaran Perdana (DCP) Code No: DCP-2017$020 / 2$.

\section{REFERENCES}

[1] J. S. K. Ooi, S. A. Ahmad, Y. Z. Chong, S. H. M. Ali, G. Ai, and H. Wagatsuma, "Driver emotion recognition framework based on electrodermal activity measurements during simulated driving conditions," in 2016 IEEE EMBS Conference on Biomedical Engineering and Sciences (IECBES), 2016, pp. 365-369.

[2] Kementerian Pengangkutan Malaysia. Statistik Pengangkutan Malaysia 2015. ISSN: 0128-2778

[3] L. Dell'Olio, A. Ibeas, and P. Cecín, "Modelling user perception of bus transit quality," Transp. Policy, vol. 17, no. 6, pp. 388-397, 2010.

[4] K. KATO, H. MIYAZAKI, T. SOMA, and M. TAKAGI, "Big Data Analytics in the Cloud-System Invariant Analysis Technology Pierces the Anomaly-," NEC Tech. J., vol. 9, no. 2, pp. 85-89, 2015.

[5] A. Habibi and A. A. M. Ariffin, "Value as a medical tourism driver interacted by experience quality," Anatolia, vol. 30, no. 1, pp. 35-46, 2019.

[6] M. Mohanty and A. Gupta, "Factors affecting road crash modeling," J. Transp. Lit., vol. 9, no. 2, pp. 15-19, 2015.
[7] Obaidat M.T, Ramadan T.M. Traffic accidents at hazardous locations of urban roads. Jordan Journal of Civil Engineering Vol. 6(4), pp.436-447.2012.

[8] Karlaftis M.G \& Golias I. Effects of road geometry and traffic volumes on rural roadway accident rates. Accident Analysis and Prevention, Vol. 34, pp.357-365. 2002.

[9] Bao, S. \& Boyle, L. N. Age-related differences in visual scanning at median-divide highway intersections in rural areas. Accident Analysis and Prevention, Vol.41, pp.146-152. 2009.

[10] Krug, E. G., Sharma G. K. \& Lozano R. The global burden of injuries. American Journal of Public Health, 90:523-526. 2000.

[11] Mercy JA et al. Public health policy for preventing violence. Health Affairs, 7-29. 1993.

[12] Mohan, D., Tiwari, G., Khayesi, M. \& Nafukho, F. M. Road traffic injury prevention training manual. World Health Organization, India. 2008.

[13] Munzilah Md. Rohani, Devapriya Chitral Wijeyesekera, Ahmad Tarmizi Abd. Karim. Bus Operation, Quality Service and The Role of Bus Provider and Driver. Malaysian Technical Universities Conference on Engineering \& Technology 2012, MUCET 2012. Procedia Engineering 53 (2013), pg 167 - 178. 2013.

[14] Joewono T.B, Hisashi Kubota. Safety and Security Improvement in Public Transportation based on Public Perception in Developing Countries. Department of Civil \& Environmental Engineering, Saitama University, Japan. 2005.

[15] Mirko V, Dragana M.N, Miodrag S. Fuzzy Petri Net Based Reasoning for the Diagnosis of Bus Condition, $7^{\text {th }}$ Seminar on Neural Network Application in Electrical Engineering, NEUREL 2004. 2004.

[16] Siti Zubaidah Ibrahim et al. Kajian Rekabentuk Sistem Keselamatan (Tali Pinggang) Bagi Penumpang Bas Komersial di Semenanjung Malaysia. $2^{\text {nd }}$ International Conference on Creative Media, Design \& Technology (REKA2016). 2016.

[17] Osman, M. R. \& Abas, F. Safety Practices among Bus Operators during Wee Hour Operations. International Journal of Social, Behavioral, Educational, Economic, Business and Industrial Engineering, Vol.4, No.11. 2010.

[18] Mohd Jawi, Z., Zainal Abidin, A. N. S., Ghani, Y. \& Osman, M. R. News and Newsworthiness Factor in In-depth Crash Investigation and Reconstruction. Proceeding of Conference of Asean Road Safety 2015. 2015.

[19] Hassan, R., Jubair, AM., Azmi, K. \& Bakar, A. Adaptive congestion control mechanism in CoAP Application Protocol for Internet of Things (IoT). 2016 International Conference on Signal Processing and Communication, ICSC 2016; Noida; India. Institute of Electrical and Electronics Engineers Inc. 2016.

[20] Ebole Alpha F., Prof Omotosha O.J (2014). Vehicle Health Monitoring System in A Developing Nation. IJECS Vol.3 Issue 5, May 2014, Page 6238-6249

[21] The Research Council (2009). Road Safety Research Program (RSRP)

[22] Jing, Q., Vasilakos, A. V., Wan, J., Lu, J., \& Qiu, D. Security of the Internet of Things: perspectives and challenges. Wireless Networks, 20(8), 2481-2501. 2014.

[23] Sundmaeker, H., Guillemin, P., Friess, P., \& Woelfflé, S. Vision and Challenges for realising the Internet of Things. Cluster of European Research Projects on the Internet of Things, European Commision. 2010.

[24] Tsai, C. W., Lai, C. F., \&Vasilakos, A. V. Future Internet of Things: open issues and challenges. Wireless Networks, 20(8), 2201-2217. 2014.

[25] Aceto, G. Botta, A. Donato, W. \& Pescape, A. Cloud Monitoring: A survey. Computer Network (2013), 1286-1389. Published by Elsevier B.V. 2013.

[26] Nuawi, M. Z., Abdullah, S., Ismail, A. R., Zulkifli, R., Zakaria, M. K., \& Hussin, M. F. H. A study on ultrasonic signals processing generated from automobile engine block using statistical analysis. WSEAS Transactions on Signal Processing, 4(5), 279-288. 2008.

[27] Fatema, K., Emeakaroha, V. C., Healy, P. D., Morisson, J. P. \& Lynn, T. A survery of Cloud monitoring tools: Taxonomy, capabilities and objectives. J.Parallel Distribu. Comput. 74(2014) 2918-2933. 2014.

[28] Alhamazani, K., Rajan, R., Mitra, K., Rabhi, F., Jayaraman, P. P., Khan, S. U., Guabtni, A. \& Bhatnagar, V. An overview of the commercial cloud monitoring tools: research dimensions, design issues, and state-of-the-art. Computing, 97(4), 357-377. 2015. 